\title{
Tendinopathy and Sports: Understanding the Problem and Options of Management-perspectives from Physiotherapy, Sports Medicine, and Orthopedics
}

\author{
${ }^{1}$ Himmat S Dhillon, ${ }^{2}$ Sidak Dhillon, ${ }^{3}$ Vikas Bachhal, ${ }^{4}$ Mandeep S Dhillon
}

\begin{abstract}
Tendinopathies are perhaps the leading cause of sportsrelated overuse injuries necessitating visit to an expert. Increased general public participation in sports and growing intensity of elite level sport had further warranted more attention and research into pathophysiology and management of tendenopathies. As a result, its management has seen enormous changes in the last few decades. The newer research methodologies applied to diagnostic and therapeutic aspects have generated a plethora of literature, which has helped sports medicine experts. However, these newer modalities have also added to the confusion among many. This review aims to present current understanding of pathophysiology of tendinopathies and evidence of success or failure of several modalities in current use.
\end{abstract}

Keywords: Exercise, Management, Orthobiologics, Sports, Tendinopathy.

How to cite this article: Dhillon HS, Dhillon S, Bachhal V, Dhillon MS. Tendinopathy and Sports: Understanding the Problem and Options of Management-perspectives from Physiotherapy, Sports Medicine, and Orthopedics. J Postgrad Med Edu Res 2017;51(4):175-181.

Source of support: Nil

Conflict of interest: None

\section{INTRODUCTION}

Over the past few decades, advancements in technology and research methods have allowed researchers from various fields to answer questions that may have eluded their predecessors. The fields of sports medicine and

\footnotetext{
${ }^{1}$ Consultant, ${ }^{2}$ Junior Resident, ${ }^{3}$ Assistant Professor ${ }^{4}$ Professor and Head

${ }^{1}$ Department of Physiotherapy, Medwest Health Care, Melbourne Victoria, Australia,

${ }^{2}$ Department of Sports Medicine and Arthroscopy, Sri Ramachandra Medical College and Research Institute, Chennai India

${ }^{3,4}$ Department of Orthopaedics, Postgraduate Institute of Medical Education and Research, Chandigarh, India
}

Corresponding Author: Vikas Bachhal, Assistant Professor Department of Orthopaedics, Postgraduate Institute of Medical Education and Research, Chandigarh, India, Phone: +917087008664, e-mail: vikasbachhal@gmail.com physiotherapy too have benefited, and through various computer programs and wearable equipment, we now have the means for efficient injury prevention and management. However, there are still a significant number of ailments that lack adequate understanding, and where clinicians and researchers have failed to reach a common consensus over fixed pathophysiological processes that may underpin them; tendinopathy is one such disorder, which even in the 21st century eludes a well-defined management protocol.

Tendinopathy has been used as an umbrella term to describe a spectrum of changes that occur in damaged or diseased tendons in the upper and lower limbs. ${ }^{1}$ Tendinopathy or tendinosis is a common, yet highly debated disorder of the tendons, seen in individuals of all age groups, most frequently in the active adult population. The disorder is characterized by localized tenderness and pain, which is significantly exacerbated when the load on the tendon is increased, resulting in loss of function and performance. ${ }^{2}$ Despite its frequent occurrence, the exact etiopathogenesis of the pathological process is still not crystal clear, and researchers and clinicians continue to debate the presence or absence of an inflammatory component in tendinopathy at all sites. ${ }^{3}$

Cook and Purdam ${ }^{4}$ proposed the occurrence of tendon pathology in a continuum, describing it as occurring in three overlapping phases. Their theory describes the first phase as reactive tendinopathy, a noninflammatory response to acute overload or unaccustomed activity in young individuals, who usually experience pain with increased tendon loading. Reactive tendinopathy is followed by tendon dysrepair/failed healing occurring as a result of chronic overloading of the tendon. The authors report collagen separation and matrix disorganization accompanied by neovascular ingrowth. The pathology progresses to degenerative tendinopathy, exhibiting areas of cell death, which, if severe enough, may evolve to tendon rupture. It is a well-documented fact that degenerative tendinopathy is more prevalent in the older population, where it has little capacity for reversibility. As a clinician, especially in a sports setting, it is important to understand that pathological tendons are not always painful and pain can occur anywhere on the tendon pathology spectrum. ${ }^{1}$ 


\section{REVIEW OF LITERATURE}

Tendon pain has the potential to be highly debilitating, especially in elite athletes, who tend to exhibit deterioration in their athletic function and performance. ${ }^{5}$ Evidencebased management encourages clinicians to treat patients with the best possible protocols and, therefore, it is extremely important for a sports physiotherapist to be aware of optimal treatments in order to ensure highquality athletic performance.

To determine the optimal treatment protocols available, an extensive literature search was conducted in PubMed, Cochrane Library, Google Scholar, and Medline using the following key words: tendinopathy, tendinosis, conservative, management, physical therapy, sports, exercise. The search was restricted to randomized controlled trials (RCTs), systemic reviews, reviews, and meta-analysis between the years 2009 and 2016.

\section{Tendon Loading}

Literature search revealed that tendon loading through various forms of exercise is being employed as the favored management and is backed by strong evidence demonstrating significant improvements in pain, function, athletic performance, and patient satisfaction in patients suffering from chronic tendinopathy. Additionally, tendon loading through eccentric training has shown to have structural benefits including improved collagen production, which has positive short- and long-term effects of the tendon structure. ${ }^{4}$

Malliaras et $\mathrm{al}^{6}$ conducted a systemic review to determine the optimum loading programs for patients suffering from Achilles and patellar tendinopathy. Their review of 32 RCTs demonstrated improved clinical outcomes as a result of improved neuromuscular performance. However, they failed to observe any superior benefits of isolated eccentric training when compared with eccentric-concentric training and heavy-slow resistance (HSR) training. Although further research is warranted in various forms of tendon loading, a plethora of evidence exists regarding the benefits of eccentric training in tendinopathy. A randomized trial conducted by Beyer et $\mathrm{al}^{7}$ comparing HSR training to eccentric training demonstrated significant improvement in pain and function in patients with chronic midportion Achilles tendinopathy using both forms of training. However, there was a significant difference in patient satisfaction and exercise compliance in favor of HSR training. A meta-analysis regarding eccentric training on Achilles tendinopathy, patellar tendinopathy, and common wrist extensor tendinopathy exhibited beneficial outcomes regarding pain, function, and return to activity/ sport. ${ }^{8}$ Another systemic review of 13 RCTs found that eccentric training yields improvements in pain and function in the management of patellar tendinopathy. ${ }^{9}$ In a recent review of 11 RCTs reviewed, Ortega-Castillo and Medina-Porqueres ${ }^{10}$ concluded that there was moderate evidence in favor of eccentric training for reducing pain and improving strength in upper limb tendinopathies, recommending its inclusion in rehabilitation programs. In an RCT involving 120 patients suffering from chronic lateral elbow tendinopathy, Peterson et $\mathrm{al}^{11}$ compared eccentric with concentric loading. They discovered that patients in the eccentric training group exhibited significantly superior results compared with the concentric group in terms of pain reduction and muscle strengthening after a 3-month intervention. Moreover, these improvements were maintained at a 1-year follow-up.

As evidence suggests, tendon loading has proven highly beneficial in managing chronic tendinopathies in the upper and lower limbs. On the contrary, tendon loading in acute or reactive tendinopathy should be avoided and management should aim to reduce tendon load. ${ }^{5}$ Isometric exercise is an emerging form of loading that has been experimented with in painful tendons, especially during in-season rehabilitation where eccentric training would potentially aggravate tendon pain and is not a viable option. An RCT of 29 athletes with patellar tendon pain concluded that both isometric and isotonic exercise programs were capable of significantly reducing tendon pain at a 4 -week follow-up. ${ }^{12}$ Rio et al ${ }^{13}$ assessed the immediate effects of isometric and isotonic training in six athletes with patellar tendon pain and their randomized cross-over study demonstrating significant reduction in pain immediately after one bout of exercise in favor of isometric training. ${ }^{13}$ Furthermore, these results were sustained even 45 minutes following the exercise bout. In another midseason clinical trial, Rio et $\mathrm{al}^{14}$ demonstrated isometric training to be significantly superior to isotonic training which exhibited immediate reduction in pain, which was sustained at 1-week and 4-week follow-up.

\section{Electrotherapy Modalities}

\section{Shock Wave Therapy}

Shock wave therapy is another area of interest and can potentially be a beneficial modality for conservative management of tendinopathy. In a recent meta-analysis of 13 studies, Mani-Babu et $a 1^{15}$ examined the effectiveness of extracorporeal shock wave therapy (ESWT) in commonly occurring tendinopathies of the lower limb. They found moderate evidence in favor of ESWT over home-based exercises and corticosteroid injections when treating greater trochantric pain syndrome and Achilles tendinopathy. Interestingly, they also discovered that ESWT was more effective in managing insertional Achilles 
tendinopathy when compared with eccentric exercise. Additionally, combination of eccentric training with ESWT was shown to be more beneficial when compared with eccentric training alone. In an RCT consisting of 68 patients with chronic Achilles tendinopathy and a history of failed management, Rompe et $\mathrm{al}^{16,17}$ found that combining ESWT with eccentric training yielded significant improvements in pain and function at a 4-month follow-up in midportion Achilles tendinopathy and at 1 year in insertional Achilles tendinopathy. These results should encourage clinicians to administer ESWT as an adjunct to eccentric training. Despite the increasing interest in ESWT in the management of tendinopathy, there is very limited research of its effectiveness in the upper limb. Galasso et $\mathrm{al}^{18}$ conducted an RCT to determine its effectiveness in 20 patients with noncalcifying supraspinatus tendinopathy, demonstrating significant improvements in pain and range of movement compared with baseline and the placebo group. Although further research is warranted in the area, current management should incorporate ESWT as an adjunct to eccentric training, especially in the lower limb.

\section{Laser Therapy and Therapeutic Ultrasound}

Low-level laser therapy (LLLT) has been proposed as a management option for tendinopathy. A systemic review with meta-analysis analyzed 17 RCTs to determine the clinical effectiveness of LLLT on pain and function in shoulder tendinopathy. ${ }^{19}$ The authors concluded that LLLT produced clinically significant improvements in shoulder pain and function when used as an adjunct to exercise therapy and even as monotherapy. Tumilty et $\mathrm{al}^{20}$ conducted a double-blind RCT including to study the effect of photomodulation and eccentric exercises in 80 participants with chronic Achilles tendinopathy. Their results demonstrated clinically significant improvements in pain and function at a 12-week follow-up in favor of photomodulation being used as an adjunct to eccentric training twice a week. These studies demonstrate the potential of laser therapy as a treatment option in the future as further research in this area is warranted.

Therapeutic ultrasound is commonly used for upper and lower limb tendinopathy. However, there is very low-quality evidence for its efficacy in improving pain and function as demonstrated by in a systemic review of 11 RCTs. ${ }^{21}$

\section{Glyceryl Trinitrate}

Although glyceryl trinitrate (GTN) patches are used in the management of tendinopathy by clinicians in managing acute and chronic patients, there is conflicting evidence regarding its long-term and short-term efficacy.
Its effectiveness in reducing pain in acute and chronic tendinopathies was demonstrated in a systemic review including 446 patients, over seven RCTs, and comparative clinical trials. ${ }^{22}$ The authors concluded that not only did topical GTN reduce pain in daily activities, it also enhanced tendon strength. Bokhari and Murrell ${ }^{23}$ conducted three RCTs to assess the long-term benefits of GTN patches in noninsertional Achilles tendinopathy, lateral elbow tendinopathy, and supraspinatus tendinopathy. At a 3-year follow-up, only noninsertional Achilles tendinopathy showed significant improvement whereas no additional benefits where noted in any patient at a 5-year follow-up. Nonetheless, the authors demonstrated short-term benefits of GTN patches in reducing pain in lateral epicondylitis. Owing to the limited evidence and conflicting results, the treating clinician should make a decision on administering a GTN patch. Patients using GTN patches have also reported of significant incidences of headaches and need to be cautioned by the clinician prior to its use. ${ }^{22,24}$

\section{Manual Therapy}

Soft-tissue mobilization has been a part of management protocols for tendinopathies. A systemic review and metaanalysis conducted by Desjardins-Charbonneau et $\mathrm{al}^{25}$ demonstrated low-level evidence for efficacy of soft-tissue mobilization for patients with rotator cuff tendinopathy. Furthermore, an RCT comparing the efficacy of soft-tissue mobilization with a supervised exercise program concluded no significant benefits of soft-tissue mobilization in reducing pain in rotator cuff tendinopathy. ${ }^{26}$

\section{Emerging Concepts of Managing Tendinopathy}

\section{Tendon Neuroplastic Training}

The exact source of tendon pain still eludes us, and this is touted as one of the prime reasons for failed tendon rehabilitation by some authors, as they debate over local and centrally mediated pain. In a recent narrative review, Rio et $\mathrm{al}^{27}$ proposed a new approach to rehabilitation where they employed an exercise protocol using externally paced strength training. Their new approach aimed to restore corticospinal control of the muscle tendon complex by employing isometric and isotonic strengthening in nine athletes, administering external paced resistance using a metronome capable of inducing excitability and inhibition. Even though their results demonstrated significant pain reduction with both forms of exercise at a 4-week follow-up, isometric training had significant immediate reduction in pain. This trial is the first of its kind and gives direction to future studies in this area with larger patient groups. 


\section{Nutritional Intervention}

Nutrition has been studied for many decades, and sports nutrition has gained significant importance when training and rehabilitating elite athletes. Additionally, as a team approach to rehabilitation in sports setting may not always be an option, it is beneficial for a sports physiotherapist to be aware of nutritional interventions available to aid the healing process of tendons. However, research in this area is extremely limited and a systematic review by Curtis $^{28}$ suggests that nutritionally supplementing whey protein, protein, glutamine, and amino acids to the diet could promote protein and collagen synthesis in the healing human tendon. Although the authors reviewed 110 studies, animal trials were also included. Nonetheless, only results relevant to human trials have been discussed in this essay.

\section{Orthopedics and Sports Medicine Aspects}

It is the opinion of the senior author (MSD) that sportsrelated tendinopathies in the acute phase respond well to a supervised rehabilitation protocol, with limited pharmacological interventions..$^{29}$ The current understanding is that the problem is not of an inflammatory nature, and hence there is a limited role of pharmacological agents; nevertheless, in the acute stage, the judicious use of nonsteroidal anti-inflammatory medication can help. The best suited under some circumstances could be Ibuprofen, probably best suited for the so-called "reactive tendinopathy" stage, as this can have an inhibitory effect on some ground substance proteins responsible for tendon swelling.

Modern understanding of the pathology has made it clear that a majority of the sports-related cases have issues with repetitive overload, and subsequent problems in healing. We now have a better understanding of the role of various growth factors and cells in the process of tendon healing, ${ }^{30}$ making Orthopods consider options in sportsrelated tendinopathies where the healing processes can be enhanced. ${ }^{31}$ The usage of platelet-rich plasma (PRP) has become relatively frequent, with well-selected indications, in cases that have failed all other physical therapy modalities plus a well-structured rehabilitation protocol. Our work on lateral epicondylitis, ${ }^{32}$ compared a single injection of leukocyte-poor (type-4) with bupivacaine injections, and it has shown good improvement in pain and function for recalcitrant lateral epicondylitis. This has also been corroborated by other research (Table 1), ${ }^{32-36}$ although larger multicentric studies are needed to recommend this as the best modality of management.

Another area of concern for sportspersons is the rotator cuff, and this is notorious for not healing in the distal part, which is the area involved in sports-related injuries. The distal part of the rotator tendon heals poorly, and PRP with its concentration of growth factors has the potential to stimulate tendon healing. Although PRP has been used to augment rotator cuff repairs, the evidence does not support its use in that scenario (Table 2) ${ }^{37-39}$ Nevertheless, there is some inconclusive evidence that PRP as a conservative option may help, ${ }^{40}$ but it may be too early to advocate its routine use at this stage.

Patellar tendinopathy is commonly encountered in jumping athletes and PRP injections may help in cases of refractory pin unresponsive to standard physiotherapeutic measures. Many studies have been conducted and some are ongoing, and they are grouped in Table $3{ }^{41,42}$

Although used extensively, PRP and other orthobiological products are still not proven to be effective beyond doubt. Nevertheless, the increasing use and dependence of sports physicians and orthopedicians on this modality to sort out what is essentially an overuse phenomenon reflects on the changing paradigms in modern sports medicine.

Table 1: Summary of studies using PRP for resistant lateral epicondylitis (modified from Dhillon et al $^{30,31}$ )

\begin{tabular}{|c|c|c|c|c|c|c|}
\hline Authors & Study type & $\begin{array}{l}\text { Patients } \\
\text { studied }\end{array}$ & Control & $\begin{array}{l}P R P \\
\text { type }\end{array}$ & Outcome measure & Results \\
\hline $\begin{array}{l}\text { Mishra and } \\
\text { Pavelko }\end{array}$ & Cohort study & $\begin{array}{l}15 \text { cases vs } \\
5 \text { controls }\end{array}$ & Bupivacaine & $1 \mathrm{~A}$ & VAS, Mayo elbow score & $\begin{array}{l}81 \% \text { reduction in pain in PRP } \\
\text { group at } 6 \text { months }\end{array}$ \\
\hline Creaney et $\mathrm{al}^{34}$ & $\begin{array}{l}\text { Prospective } \\
\text { randomized } \\
\text { trial }\end{array}$ & $\begin{array}{l}80 \text { cases vs } 70 \\
\text { controls }\end{array}$ & $\begin{array}{l}\text { Autologous } \\
\text { blood }\end{array}$ & 1B & PRTEE & $\begin{array}{l}\text { Improvement in PRTEE at } 6 \\
\text { months } 35.8 \text { in PRP and } 46.8 \text { in } \\
\mathrm{ABI} \text { group with higher conversion } \\
\text { to surgery in } \mathrm{ABI} \text { group }\end{array}$ \\
\hline Thanasas et $\mathrm{al}^{35}$ & RCT & $\begin{array}{l}14 \text { cases vs } 14 \\
\text { controls }\end{array}$ & $\begin{array}{l}\text { Autologous } \\
\text { blood }\end{array}$ & $1 \mathrm{~A}$ & $\begin{array}{l}\text { VAS, Liverpool elbow } \\
\text { score }\end{array}$ & $\begin{array}{l}70.8 \% \text { improvement in PRP } \\
\text { group and } 57.8 \% \text { in the } \\
\text { autologous blood group at } 6 \\
\text { months }\end{array}$ \\
\hline Behera et $\mathrm{al}^{32}$ & $\begin{array}{l}\text { Prospective } \\
\text { randomized } \\
\text { trial }\end{array}$ & $\begin{array}{l}15 \text { cases vs } 10 \\
\text { controls }\end{array}$ & Bupivacaine & $1 \mathrm{~A}$ & $\begin{array}{l}\text { VAS, modified Mayo } \\
\text { clinic performance index } \\
\text { for elbow, Nirschl score }\end{array}$ & $\begin{array}{l}\text { Significant improvement at } 6 \\
\text { months and } 1 \text { year for all scores }\end{array}$ \\
\hline
\end{tabular}

PRTEE: Patient-rated tennis elbow evaluation; $A B I$ : Autologous blood injection 
Tendinopathy and Sports

\begin{tabular}{|c|c|c|c|c|c|}
\hline Authors & $\begin{array}{l}\text { Study } \\
\text { type }\end{array}$ & $\begin{array}{l}\text { Patients } \\
\text { studied }\end{array}$ & Control & Outcome measure & Results \\
\hline Randelli et $\mathrm{al}^{37}$ & $\mathrm{RCT}$ & $\begin{array}{l}26 \text { cases vs } \\
27 \text { controls }\end{array}$ & $\begin{array}{l}\text { Nonapplication } \\
\text { of PRP }\end{array}$ & $\begin{array}{l}\text { SST, UCLA score, Constant } \\
\text { score }\end{array}$ & $\begin{array}{l}\text { PRP positively affected cuff rotator } \\
\text { healing of grade I and II tears }\end{array}$ \\
\hline Rha et $\mathrm{al}^{38}$ & RCT & & Dry needling & $\begin{array}{l}\text { Shoulder pain and disability } \\
\text { index, passive ROM }\end{array}$ & $\begin{array}{l}\text { Clinical effect of the PRP injection was } \\
\text { superior to the dry needling from } 6 \\
\text { weeks to } 6 \text { months after initial injection }\end{array}$ \\
\hline Weber et $\mathrm{al}^{39}$ & RCT & $\begin{array}{l}30 \text { cases vs } \\
30 \text { controls }\end{array}$ & $\begin{array}{l}\text { Nonapplication } \\
\text { of PRP }\end{array}$ & $\begin{array}{l}\text { UCLA score, VAS, SST, } \\
\text { ASES score }\end{array}$ & $\begin{array}{l}\text { No significant difference in VAS scores } \\
\text { between groups and no statistically } \\
\text { significant differences in recovery of } \\
\text { motion, SST, or ASES scores }\end{array}$ \\
\hline
\end{tabular}

ROM: Range of motion; SST: Simple shoulder test; ASES: American shoulder and elbow surgery; UCLA: University of California, Los Angeles shoulder scale

Table 3: Studies using PRP for patellar tendinopathy (modified from Dhillon et $\mathrm{al}^{30,31}$ )

\begin{tabular}{llllll}
\hline Authors & Study type & Patients studied & Control & Outcome measure & Results \\
\hline Filardo et al ${ }^{41}$ & $\begin{array}{l}\text { Case-control } \\
\text { study }\end{array}$ & $\begin{array}{l}15 \text { cases vs } 16 \\
\text { controls }\end{array}$ & $\begin{array}{l}\text { Physical } \\
\text { therapy }\end{array}$ & $\begin{array}{l}\text { Tegner, EQ VAS, } \\
\text { and pain level }\end{array}$ & $\begin{array}{l}\text { Statistically significant improvement in all } \\
\text { scores at the end of the PRP injections and a } \\
\text { further improvement was noted at } 6 \text { months }\end{array}$ \\
${\text { Gosens et al }{ }^{42}}^{\text {Prospective }}$ & 36 patients & - & VAS, VISA & $\begin{array}{l}\text { Statistically significant improvement in VAS } \\
\text { and VISA scores in patients receiving PRP } \\
\text { injections }\end{array}$ \\
\hline
\end{tabular}

Table 4: Pain provocation tests for lower limb tendinopathy

\begin{tabular}{|c|c|c|}
\hline Tendon & Low-load tests & High-load tests \\
\hline Achilles tendon & Single leg heel raise & Hop \\
\hline Patellar tendon & Decline squats & $\begin{array}{l}\text { Single leg highjump, } \\
\text { landing from height }\end{array}$ \\
\hline $\begin{array}{l}\text { Hamstring } \\
\text { tendon }\end{array}$ & $\begin{array}{l}\text { Single leg bent knee } \\
\text { bridging }\end{array}$ & Single leg dead lift \\
\hline Gluteal tendon & Single leg stance & Hop \\
\hline
\end{tabular}

\section{Areas of Clinical Uncertainty}

\section{The Pathology of Tendinopathy}

To make good clinical decisions regarding management, the understanding of the pathological process of a disorder is essential. The exact mechanisms underpinning tendinopathy have eluded medical professionals with some authors proposing an inflammatory component ${ }^{4}$ and others opposing this notion and claiming that acute tendinopathy is a noninflammatory response. ${ }^{43}$ This debate has resulted in experimentation with various physiotherapy and medical interventions, majority of which have been successful in determining an effective concrete solution to the most effective management of tendinopathies (Table 4).

\section{Pain in Tendinopathy}

Pain is the primary limiting factor in regard to function and performance. Interestingly, a tendon can be pain-free even with the presence of pathology leading to speculation on whether the pain is a locally or centrally mediated response. Neovascular ingrowth following collagen disorganization is proposed to be locally responsible for tendon-related pain. ${ }^{44}$ On the contrary, Rio et $\mathrm{al}^{45}$ have proposed a more centrally mediated response with multiple potential contributors to pain.

\section{Optimum Tendon Loading}

Although the pathology of tendinopathy is still elusive, it is known that unaccustomed tendon loading is responsible for development of tendinopathy. However, the amount of load that induces tendon pathology is still unknown. ${ }^{4}$ Therefore, sports physiotherapists need to develop exercise programs with sufficient rest intervals between bouts, especially during trainings in season. The sports physiotherapists need to construct programs that ensure systemic progression of load in order to achieve enhancement of the muscle-tendon unit capacity. Studies have shown type- 1 collagen takes up to 3 days to respond to high-load training, and daily bouts of high-load training place excessive strain on the tendon, eventually leading to injury. ${ }^{46}$ As per discussions during the lecture on management of tendinopathy by Mr David Spurier, sports physiotherapists should consider employing an approach of high-load training, followed by days of low-load training followed by medium-load training to ensure optimum rest to allow tendons to accommodate to the loads.

\section{Clinical Practice in Sports Physiotherapy}

\section{Quantification of Tendon Function and Symptoms}

- Victorian Institute of Sport Assessment (VISA): The questionnaire has shown to have good test-retest, 
intrarater, and interrater reliability and is used as a tool for functional assessment and severity of symptoms in patients with tendinopathy. ${ }^{47,48}$

- Loading/pain provocation tests: Tendon loading and pain provocation tests used with visual analog scale (VAS) to monitor pain summarized in Table 3 assist the sports physiotherapist to monitor the athlete's tendon response to training loads. ${ }^{5}$

Managing in-season acute tendinopathy and progressive loading in sports persons:

- Minimize tendon compression and tension at various sites in the tendon that have a potential to overload, especially the enthesis. ${ }^{2}$

- Progressive loading in the form of isometric exercises should be initiated as they have the potential to inhibit pain immediately and can be repeated several times a day. ${ }^{14}$

- Depending on availability, ESWT, laser therapy, and soft-tissue mobilization can be delivered for management of pain. ${ }^{15}$

- Modification of training in order to avoid heavy tendon-loading exercises on consecutive days. ${ }^{46}$

\section{Management of Chronic Tendinopathy}

- From the physiotherapist's point of view, the literature review suggests that eccentric training should the treatment of choice for managing chronic upper and lower limb tendinopathies and administering ESWT as an adjunct can potential yield long-term clinically significant improvements in function and pain.

- As mentioned previously, the sports physiotherapist needs to monitor the tendon response to loading and training modifications should ensure that high-load training is not repeated on consecutive days.

- Interventions by sports physicians or orthopedic surgeons are limited to the use of injections. As stated previously, lateral epicondylitis reacts well to PRP injections when other noninterventional methods have failed. The debate still rages about the platelet concentration, leukocyte filtration, and frequency of injections. Nevertheless, this is a procedure more frequently incorporated by the sports physician in their management repertoire.

\section{REFERENCES}

1. Scott A, Backman LJ, Speed C. Tendinopathy: update on pathophysiology. J Orthop Sports Phys Ther 2015 Nov;45(11): 833-841.

2. Ackermann PW, Renström P. Tendinopathy in sport. Sports Health 2012 May;4(3):193-201.

3. Rees JD, Stride M, Scott A. Tendons-time to revisit inflammation. Br J Sports Med 2014 Nov;48(21):1553-1557.
4. Cook JL, Purdam CR. Is tendon pathology a continuum? A pathology model to explain the clinical presentation of loadinduced tendinopathy. Br J Sports Med 2009 Jun;43(6):409-416.

5. Cook JL, Purdam CR. The challenge of managing tendinopathy in competing athletes. Br J Sports Med 2014 Sep;48(7): 506-509.

6. Malliaras P, Barton CJ, Reeves ND, Langberg H. Achilles and patellar tendinopathy loading programmes: a systematic review comparing clinical outcomes and identifying potential mechanisms for effectiveness. Sports Med 2013 Apr;43(4): 267-286.

7. Beyer R, Kongsgaard M, Hougs Kjaer B, Øhlenschlaeger T, Kjaer M, Magnusson SP. Heavy slow resistance versus eccentric training as treatment for achilles tendinopathy: a randomized controlled trial. Am J Sports Med 2015 Jul;43(7):1704-1711.

8. Woodley BL, Newsham-West RJ, Baxter GD. Chronic tendinopathy: effectiveness of eccentric exercise. Br J Sports Med 2007 Apr;41(4):188-198, discussion 199.

9. Larsson ME, Käll I, Nilsson-Helander K. Treatment of patellar tendinopathy-a systematic review of randomized controlled trials. Knee Surg Sports Traumatol Arthrosc 2012 Aug;20(8):1632-1646.

10. Ortega-Castillo M, Medina-Porqueres I. Effectiveness of the eccentric exercise therapy in physically active adults with symptomatic shoulder impingement or lateral epicondylar tendinopathy: a systematic review. J Sci Med Sport 2016 Jun;19(6):438-453.

11. Peterson M, Butler S, Eriksson M, Svärdsudd K. A randomized controlled trial of eccentric vs. concentric graded exercise in chronic tennis elbow (lateral elbow tendinopathy). Clin Rehabil 2014 Sep;28(9):862-872.

12. van Ark M, Cook JL, Docking SI, Zwerver J, Gaida JE, van den Akker-Scheek I, Rio E. Do isometric and isotonic exercise programs reduce pain in athletes with patellar tendinopathy in-season? A randomised clinical trial. J Sci Med Sport 2016 Sep;19(9):702-706.

13. Rio E, Kidgell D, Purdam C, Gaida J, Moseley GL, Pearce AJ, Cook J. Isometric exercise induces analgesia and reduces inhibition in patellar tendinopathy. Br J Sports Med 2015 Oct;49(19):1277-1283.

14. Rio E, van Ark M, Docking S, Moseley GL, Kidgell D, Gaida JE, van den Akker-Scheek I, Zwerver J, Cook J. Isometric contractions are more analgesic than isotonic contractions for patellar tendon pain: an in-season randomized clinical trial. Clin J Sport Med 2017 May;27(3):253-259.

15. Mani-Babu S, Morrissey D, Waugh C, Screen H, Barton C. The effectiveness of extracorporeal shock wave therapy in lower limb tendinopathy: a systematic review. Am J Sports Med 2015 Mar;43(3):752-761.

16. Rompe JD, Furia J, Maffulli N. Eccentric loading compared with shock wave treatment for chronic insertional achilles tendinopathy. A randomized, controlled trial. J Bone Joint Surg Am 2008 Jan;90(1):52-61.

17. Rompe JD, Furia J, Maffulli N. Eccentric loading versus eccentric loading plus shock-wave treatment for midportion achilles tendinopathy: a randomized controlled trial. Am J Sports Med 2009 Mar;37(3):463-470.

18. Galasso O, Amelio E, Riccelli DA, Gasparini G. Short-term outcomes of extracorporeal shock wave therapy for the treatment of chronic non-calcific tendinopathy of the supraspinatus: a double-blind, randomized, placebo-controlled trial. BMC Musculoskelet Disord 2012 Jun;13:86. 
19. Haslerud S, Magnussen LH, Joensen J, Lopes-Martins RA, Bjordal JM. The efficacy of low-level laser therapy for shoulder tendinopathy: a systematic review and meta-analysis of randomized controlled trials. Physiother Res Int 2015 Jun;20(2):108-125.

20. Tumilty S, Mani R, Baxter GD. Photobiomodulation and eccentric exercise for Achilles tendinopathy: a randomized controlled trial. Lasers Med Sci 2016 Jan;31(1):127-135.

21. Desmeules F, Boudreault J, Roy JS, Dionne C, Frémont P, MacDermid JC. The efficacy of therapeutic ultrasound for rotator cuff tendinopathy: a systematic review and meta-analysis. Phys Ther Sport 2015 Aug;16(3):276-284.

22. Gambito ED, Gonzalez-Suarez CB, Oquiñena TI, Agbayani RB. Evidence on the effectiveness of topical nitroglycerin in the treatment of tendinopathies: a systematic review and metaanalysis. Arch Phys Med Rehabil 2010 Aug;91(8):1291-1305.

23. Bokhari AR, Murrell GA. The role of nitric oxide in tendon healing. J Shoulder Elbow Surg 2012 Feb;21(2):238-244.

24. Garrick JG. Topical nitroglycerin decreases pain intensity in daily activities: a review. Clin J Sport Med 2011 Nov;21(6): 539-540.

25. Desjardins-Charbonneau A, Roy JS, Dionne CE, Frémont $\mathrm{P}$, MacDermid JC, Desmeules F. The efficacy of manual therapy for rotator cuff tendinopathy: a systematic review and metaanalysis. J Orthop Sports Phys Ther 2015 May;45(5):330-350.

26. enbursa G, Baltaci G, Atay ÖA. The effectiveness of manual therapy in supraspinatus tendinopathy. Acta Orthop Traumatol Turc 2011 May;45(3):162-167.

27. Rio E, Kidgell D, Moseley GL, Gaida J, Docking S, Purdam C, Cook J. Tendon neuroplastic training: changing the way we think about tendon rehabilitation: a narrative review. $\mathrm{Br}$ J Sports Med 2016 Feb;50(4):209-215.

28. Curtis L. Nutritional research may be useful in treating tendon injuries. Nutrition 2016 Jun;32(6):617-619.

29. Dhillon M, Gill HS. Sports injuries: what is new today? Ceylon Med J 2005;50(2):43-45.

30. Dhillon MS, Behera P, Patel S, Shetty V. Orthobiologics and platelet rich plasma. Indian J Orthop 2014 Jan-Feb;48(1):1-9.

31. Dhillon RS, Schwarz EM, Maloney MD. Platelet-rich plasma therapy - future or trend? Arthritis Res Ther 2012 Aug;14(4):219.

32. Behera P, Dhillon M, Aggarwal S, Marwaha N, Prakash M. Leukocyte-poor platelet-rich plasma versus bupivacaine for recalcitrant lateral epicondylar tendinopathy. J Orthop Surg (Hong Kong) 2015 Apr;23(1):6-10.

33. Mishra A, Pavelko T. Treatment of chronic elbow tendinosis with buffered platelet-rich plasma. Am J Sports Med 2006 Nov;34(11):1774-1778.

34. Creaney L, Wallace A, Curtis M, Connell D. Growth factorbased therapies provide additional benefit beyond physical therapy in resistant elbow tendinopathy: a prospective, single-blind, randomised trial of autologous blood injections versus platelet-rich plasma injections. Br J Sports Med 2011 Mar;45(12):966-971.

35. Thanasas C, Papadimitriou G, Charalambidis C, Paraskevopoulos I, Papanikolaou A. Platelet-rich plasma versus autologous whole blood for the treatment of chronic lateral elbow epicondylitis: a randomized controlled clinical trial. Am J Sports Med 2011 Oct;39(10):2130-2134.

36. Mishra AK, Skrepnik NV, Edwards SG, Jones GL, Sampson S, Vermillion DA, Ramsey ML, Karli DC, Rettig AC. Efficacy of platelet-rich plasma for chronic tennis elbow: a double-blind, prospective, multicenter, randomized controlled trial of 230 patients. Am J Sports Med 2014 feb;42(2):463-471.

37. Randelli P, Arrigoni P, Ragone V, Aliprandi A, Cabitza P. Platelet rich plasma in arthroscopic rotator cuff repair: a prospective RCT study, 2-year follow-up. J Shoulder Elbow Surg 2011 Jun;20(4):518-528.

38. Rha DW, Park GY, Kim YK, Kim MT, Lee SC. Comparison of the therapeutic effects of ultrasound-guided platelet-rich plasma injection and dry needling in rotator cuff disease: a randomized controlled trial. Clin Rehabil 2013 Feb;27(2): 113-122.

39. Weber SC, Kauffman JI, Parise C, Weber SJ, Katz SD. Plateletrich fibrin matrix in the management of arthroscopic repair of the rotator cuff: a prospective, randomized, double-blinded study. Am J Sports Med 2013 Feb;41(2):263-270.

40. Filardo G, Di Matteo B, Kon E, Merli G, Marcacci M. Plateletrich plasma in tendon-related disorders: results and indications. Knee Surg Sports Traumatol Arthrosc 2016 Sep.

41. Filardo G, Kon E, Della Villa S, Vincentelli F, Fornasari PM, Marcacci M. Use of platelet-rich plasma for the treatment of refractory jumper's knee. Int Orthop 2010 Aug;34(6): 909-915.

42. Gosens T, Den Oudsten BL, Fievez E, van 't Spijker P, Fievez A. Pain and activity levels before and after platelet-rich plasma injection treatment of patellar tendinopathy: a prospective cohort study and the influence of previous treatments. Int Orthop 2012 Sep;36(9):1941-1946.

43. Fu SC, Rolf C, Cheuk YC, Lui PP, Chan KM. Deciphering the pathogenesis of tendinopathy: a three-stages process. Sports Med Arthrosc Rehabil Ther Technol 2010 Dec;2:30.

44. Alfredson $\mathrm{H}$. The chronic painful Achilles and patellar tendon: research on basic biology and treatment. Scand J Med Sci Sports 2005 Aug;15(4):252-259.

45. Rio E, Moseley L, Purdam C, Samiric T, Kidgell D, Pearce AJ, Jaberzadeh S, Cook J. The pain of tendinopathy: physiological or pathophysiological? Sports Med 2014 Jan;44(1):9-23.

46. Langberg H, Skovgaard D, Asp S, Kjaer M. Time pattern of exercise-induced changes in type I collagen turnover after prolonged endurance exercise in humans. Calcif Tissue Int 2000 Jul;67(1):41-44

47. Visentini PJ, Khan KM, Cook JL, Kiss ZS, Harcourt PR, Wark JD. The VISA score: an index of severity of symptoms in patients with jumper's knee (patellar tendinosis). Victorian Institute of Sport Tendon Study Group. J Sci Med Sport 1998 Jan;1(1):22-28.

48. Robinson JM,CookJL,Purdam C, Visentini PJ, Ross J,MaffulliN, Taunton JE, Khan KM, Victorian Institute Of Sport Tendon Study Group. The VISA-A questionnaire: a valid and reliable index of the clinical severity of Achilles tendinopathy. Br J Sports Med 2001 Oct;35(5):335-341. 